\title{
Ankilozan Spondiliti Olan Hastalarda Depresyonun, Hastalık Aktivitesi ve Yaşam Kalite Ölçekleri Üzerine Etkileri
}

The Impact of Depression on Disease Activity and Quality of Life Indices in Patients with Ankylosing Spondylitis

\section{Sibel Bakırcı Üreyen', Dilek Solmaz ${ }^{2}$}

' Sakarya Eğitim ve Araştırma Hastanesi, l̇ç Hast. Kliniği, Romatoloji Bölümü, Sakarya, Türkiye.

${ }^{2}$ Namık Kemal Üniversitesi Tıp Fakültesi Eğitim ve Araştırma Hastanesi, Iç̧ Hast. Kliniği, Romatoloji Bölümü, Tekirdağ, Türkiye

Yazışma Adresi / Correspondence:

Sibel Bakırcı Üreyen

Şirinevler Mahallesi,Adnan Menderes Cad. Sağlık Sok No:195, 54100 Adapazarı/Sakarya , Türkiye

\author{
T: 4445400 E-mail: bakircisibel@gmail.com
}

Geliş Tarihi / Received : 29.04.2018 Kabul Tarihi / Accepted : 30.05.2018

\footnotetext{
Öz

Amaç Bu çalıșmanın amacı, AS hastalarında depresyonun sıklığını ve depresyonun hastalık aktivite ve yaşam kalite ölçekleri üzerine olan etkilerini değerlendirmektir.

Sakarya Tip Dergisi, 2018, 8(2):371-378)

Gereç ve Çalışmamıza modifiye New York Kriterlerine göre AS tanısı almış 144 hasta dahil edildi. Depresyon düzeyi değerlendirilmesi için Beck

Yöntem Depresyon Ölçeği (BDÖ), anksiyete değerlendirmesi için ise Beck Anksiyete Ölçeği (BAÖ) formları kullanıldı. AS hastalarında hastalık aktivitesi Bath AS Hastalık Aktivite İndeksi (BASDAi) ile, spinal mobilite Bath AS metroloji indeksi (BASMi) ile ve fonksiyonel durum ise Bath AS fonksiyonel indeksi (BASFi) ile değerlendirildi. Yaşam kalitesini değerlendirmek için bir çok farklı indeks kullanılarak depresyon ile bu parametreler arasındaki ilişkiler analiz edildi.

Bulgular Çalısmaya dahil edilen 144 AS hastasının \%71.5'u erkekti ve ortalama yașları ise 39.07 (10.8) olarak saptandı. Hastaların \%27.5'inde BDÖ'ye göre depresyon ve \%33.6'sında BAÖ'e göre orta ve yüksek düzeyde anksiyete tespit edildi. BDÖ'ye göre depresyonda olan hastaların BASDAi ve BASFi ile ölçülen hastalık aktivitesi yüksek olarak bulundu (sırasıyla, $p=0.008, p=0.002$ ). Depresyonu olan hastalarda tüm yaşam kalite ölçeklerinde olumsuz yönde bir etkilenme vardı. Depresyonu olan hastalarda anksiyete sıklığı da yüksekti. BASDAi $\geq 4$ olan hastalarda depresyon sıklığının 1.55 kat (\%95 güvenlik aralığında 1.043-2.31, $p<0.05)$ arttığı gözlemlendi.

Sonuç AS hastalarında psikiyatrik durum değerlendirmesi klinik değerlendirmenin bir parçası olarak düșünülebilir. Depresyonun da katkıda bulunduğu yasam kalitesindeki bozulmanın düzeltilmesini hedefleyen tedavi yöntemleri, hastanın AS tedavisine uyumuna da katkı sağlayabilir.

Anahtar Ankilozan Spondilit; yaşam kalite ölçekleri; depresyon; anksiyete; Beck Depresyon Ölçeğ

Kelimele
}

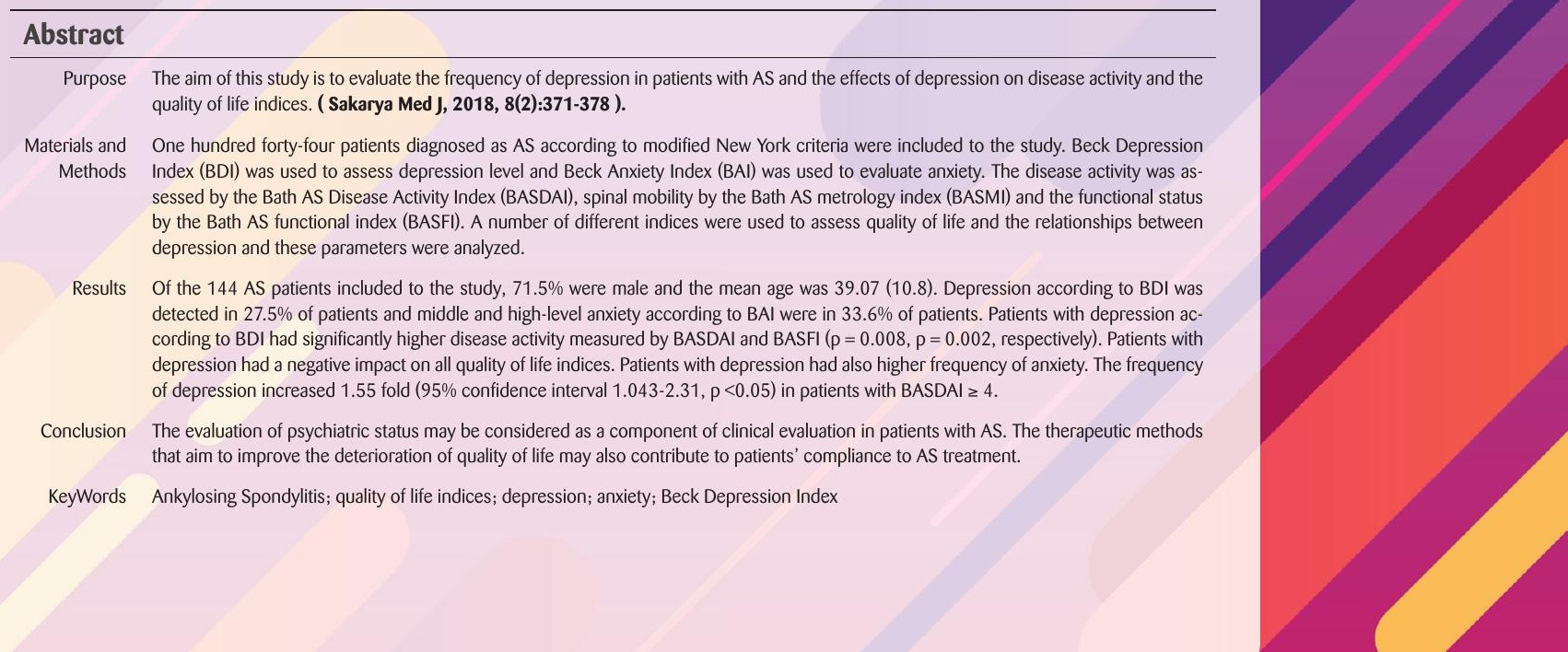


Sakarya TIp Dergisi

2018;8(2):371-378

\section{Giriş}

Spondiloartritlerin prototipi olan Ankilozan Spondilit (AS), etiyolojisi bilinmeyen, özellikle omurga ve sakroiliak eklemleri etkileyen, sistemik, kronik, inflamatuvar bir hastalıktır. ${ }^{1}$ Erkeklerde AS görülme sıklığı kadınlara göre yaklaşık 2.5 kat artmıştır ve hastaların en üretken oldukları genç yaşlarda hastalık belirtileri görülmeye başlamaktadır. ${ }^{2}$

Hareket kısıtlılıkları, ağrı ve yorgunluk nedeniyle AS, fiziksel, psikolojik ve sosyal yönden hastaların yaşamlarını ciddi ölçüde etkileyebilmektedir. Hatta bazen hastalık engellilik ve iş gücü kaybı ile dahi sonuçlanabilmektedir. ${ }^{3}$ Hastalığın hem yaşam kalitesi üzerine bu olumsuz etkileri hem de kronik ve ilerleyici seyrinden dolayı, hastalarda bazı psikiyatrik semptomlara yol açabilmektedir.

AS hastalarında en sık karşılaşılan psikiyatrik bulgular anksiyete ve depresyondur. Türkiye'de yapılan bir çalışmada, bu hasta grubundaki sıklıkları \%28 ile \%32 arasında4, dünyada ise bu sıklıklar anksiyete için \%19.5-60.9 ve depresyon için \%27.4-55.5 arasında bulunmuştur. ${ }^{5-7}$

Bazı çalışmalarda hastalık aktivitesinin artışı ve fonksiyonelliğin azalması ile depresyon, anksiyete semptomları ve uyku bozukluğu arasında önemli bir korelasyon olduğu bulunmuştur. ${ }^{8,9}$ Ayrıca, Martindale ve ark, AS hastalarında psikolojik durum değerlendirmesinin, klinik değerlendirme kadar önemli olduğunu ileri sürmüşlerdir. ${ }^{8}$

Bu çalışmanın amacı, AS hastalarında, depresyonun sıklığını belirlemek, depresyonun yaşam kalite ölçekleri, hastalık aktivite indeksleri ve fonksiyon üzerine etkilerini değerlendirmektir. Ayni zamanda, depresyon ile ilişkili hastalık faktörleri ve depresyonun bu faktörler üzerine olan etkisi de incelenmiştir.

\section{Gereç ve yöntemler:}

\section{Hastalar ve çalışmanın tasarımı}

Bu kesitsel tipte tanımlayıcı ve tek merkezli çalışmaya, 2014-2015 tarihleri arasında Namık Kemal Üniversitesi Tıp Fakültesi Eğitim ve Araştırma Hastanesi romatoloji kliniğine başvuran ve Modifiye New York Kriterlerine göre (mNY) AS tanısı almış, 18 yaş üzeri 144 hasta ardışık olarak dahil edildi ve bu hastaların hepsi çalışmaya ait formları doldurdu. ${ }^{10}$ Bu çalışma, Namık Kemal Üniversitesi Yerel Etik Kurulu tarafından onaylandı ve tüm bireyler veri toplama öncesinde bilgilendirilmiş yazılı onamını verdi.

Formların sağlıklı doldurulabilmesi için okuma yazması olmayan ve mental durumu bu formları doldurmak için yeterli olmayan bireyler çalışmaya dahil edilmedi. Ek olarak, başka bir inflamatuvar hastalığının olması, kronik psikiyatrik aktif hastalık varlığı veya öyküde olması ve üç ay içerisinde psikotropik ilaç kullanımı olması dışlama kriteri olarak kabul edildi.

\section{Klinik değerlendirmeler}

Yaş, cinsiyet, eğitim süresi, hastalığa ait semptom süresi, hastalık süresi, sigara mazuriyeti gibi genel demografik veriler ve eğer mevcut ise HLAB27, eritrosit sedimentasyon hızı (ESR), C reaktif protein (CRP) gibi laboratuvar değerleri kayıt edildi. Klinik değerlendirmeler deneyimli bir romato$\log$ (Dilek Solmaz) tarafından yapıldı. 


\section{Psikolojik Anket ve ölçümler}

Beck Depresyon Ölçeği (BDÖ): Her maddenin 0-3 arasında puan aldığı 21 sorudan oluşmaktadır. Toplam puan 0-63 arasında değişir. 17 puanın üzeri depresyon olarak kabul edilmiştir.11

Beck Anksiyete Ölçeği (BAÖ): Her maddenin 0-3 arasında puan aldığı 21 sorudan oluşmaktadır. Toplam puan 0-63 arasında değişir. 8-15 puan arası hafif anksiyete, 16-25 orta, 26-63 ağır anksiyete olarak tanımlanmıştı. ${ }^{12}$

Hastalık aktivite, şiddet ve yaşam kalitesi değerlendirilmesinde kullanılan indekler :

Hastaların ağ̊ı düzeyi $10 \mathrm{~cm}$ 'lik görsel analog skala (visual analogue scale-VAS) ile değerlendirildi. Gece ağrıSı, genel ağ̊ı, hastalık aktivitesi, genel sağık (son hafta) ve genel sağlık (son 6 ay) VAS ile değerlendirilerek kayıt edildi. ${ }^{13}$

AS hastalarının klinik hastalık aktivitesinin değerlendirilmesi için Bath AS Hastalık Aktivite İndeksi (BASDAi) (0-10), spinal mobilite değerlendirilmesi için Bath AS metroloji indeksi (BASMi) (0-10) ve fonksiyonel durumun değerlendirilmesi için ise Bath AS fonksiyonel indeksi (BASFi) (0-10) kullanıld. ${ }^{14-16}$

Hastalıkla ilişkili yaşam kalitesinin ölçümünü değerlendirmek için AS Yaşam Kalitesi Anketi (Ankylosing Spondylitis Quality of Life Questionnaire -ASQoL (0-18))16, genel yaşam kalitesi ölçeği olarak EuroQuol 5D (EQ5D (0-100))17, kısa SF-36 yaşam kalite ölçeğinin fiziksel komponent skoru (FKS)(0-100) ve mental komponent skoru (MKS) (0-100)18 ve engelliliğin değerlendirilmesi için ise Spondiloartritler için sağık değerlendirme anketi (Health Assessment Questionary for the Spondylarthropathies (HAQs (0-3)) 19 kullanıldı.

\section{İstatiksel Analiz}

Sürekli veriler, ortalama (standart sapmalar (SD)) olarak, kategorik veriler ise frekans (n) ve yüzde (\%) olarak ifade edildi. îki grup arasındaki karşılaştırmalar Mann-Whitney U testi kullanılarak yapıldı. Kategorik değişkenleri karşılaştırmak için ise ki-kare testi kullanıldı. Hastalardan oluşturulan subgruplarda ölçeklerin birbiriyle ilişkisinin incelenmesinde Spearman korelasyon analizi kullanıldı. Depresyonun, hastalık aktivite parametreleri üzerine etkisi için rölatif risk hesaplandı. İstatiksel değerlendirmede anlamlılık düzeyi olarak $p<0.05$ kabul edildi. Analiz için SPSS V-20 kullanıldı (SPSS Inc., Chicago, IL, ABD).

\section{Bulgular:}

Çalışmaya deneyimli romatoloji uzmanı tarafından tanısı konulan 144 AS hastası dahil edildi. Hastaların \%71.5'u erkek ve ortalama yaşları 39.07 (10.8) olarak bulundu. Hastaların demografik verileri, hastalık aktivite, fonksiyon ve yaşam kalite ölçeklerinin dağııımı Tablo 1 de özetlenmiştir.
Sakarya Tıp Dergisi

2018;8(2):371-378

ÜREYEN ve Ark 
Tablo 2. Depresyonu olan ve olmayan hastaların tanımlayıcı özellikleri ve hastalık karakteristiklerinin karşılaştırması

\begin{tabular}{|c|c|c|c|}
\hline & Depresyon yok n=95 & Depresyon var $n=36$ & \\
\hline Kadın* & $26 / 95$ (\% 27.4) & $13 / 36(\% 36.1)$ & \multirow{2}{*}{0.329} \\
\hline Erkek* & $69 / 95(\% 72.6)$ & $23 / 36(\% 63.9)$ & \\
\hline Yaş & $38.8(10.3)$ & $37.16(10.7)$ & 0.233 \\
\hline Eğitim süresi (yıl) & $9.17(4.1)$ & $9.81(3.6)$ & 0.744 \\
\hline Semptom süresi (yıl) & $11.99(7.5)$ & $10.86(8.5)$ & 0.238 \\
\hline Hastalık süresi (yıl) & $5.95(5.7)$ & $5.24(6.3)$ & 0.369 \\
\hline Sigara maruziyeti var* & $65 / 89(\% 73)$ & $25 / 35(\% 71.4)$ & 0.490 \\
\hline BASDAi & $3.46(2)$ & $4.56(1.9)$ & 0.008 \\
\hline BASFI & $2.45(2.5)$ & $3.98(2.8)$ & 0.002 \\
\hline BASMi & $2.82(2.1)$ & $3.23(2.2)$ & 0.329 \\
\hline Gece ağ`ısı (VAS) & $2.92(2.6)$ & $4.85(3.09)$ & 0.001 \\
\hline Genel ağıı (VAS) & $3.47(2.7)$ & $4.88(3.3)$ & 0.030 \\
\hline Hastalık aktivitesi (VAS) & $3.59(2.6)$ & $5.35(2.9)$ & 0.003 \\
\hline Genel sağlık (son hafta) (VAS) & $3.34(2.4)$ & $5.38(2.9)$ & $<0.001$ \\
\hline Genel sağlık (son 6 ay) (VAS) & $3.96(2.5)$ & $5.66(2.8)$ & 0.002 \\
\hline ASQoL & $5.5(4.7)$ & $9.77(4.3)$ & $<0.001$ \\
\hline EQ5D & $2.73(1.9)$ & $4.63(1.7)$ & $<0.001$ \\
\hline HAQs & $0.48(0.4)$ & $0.81(0.5)$ & 0.001 \\
\hline Beck Anksiyete Ölçeği & $8.45(7.4)$ & $25.47(13.3)$ & $<0.001$ \\
\hline FKS & $44.76(8.4)$ & $38.44(10.8)$ & 0.002 \\
\hline MKS & $46.89(8.1)$ & $33.31(6.3)$ & $<0.001$ \\
\hline Anti-TNF tedavi* & $58 / 95$ (\% 61.1) & $24 / 36(\%$ 66.7) & 0.686 \\
\hline HLAB27 pozitif* & 48/64 (\% 75) & $23 / 26(\% 88.5)$ & 0.254 \\
\hline
\end{tabular}

Tablonun içindeki veriler ortalama (SD) veya n / toplam n yüzde (\%)* olarak verildi. ASQoL: Ankilozan Spondilit Yaşam Kalitesi Ölçeği; BASDAi:Bath Ankylosing Spondylitis Hastalık Aktivite İndeksi; BASMi: Bath Ankylosing Spondylitis Metroloji İndeksi; BASFi: Bath Ankylosing Spondylitis Fonksiyonel İndeksi; EQ5D: EuroQuol 5D; HAQs: Spondiloartritler için sağlkk değerlendirme anketi (Health Assessment Questionary For The Spondylarthropathies); MKS: mental komponent skoru; FKS: fiziksel komponent skoru; VAS: görsel analog skala (visual analogue scale).

BDÖ ile tüm hastalık aktivite parametreleri ve yaşam kalite ölçekleri arasında pozitif yönde bir korelasyon mevcuttu. SF-36'nin MKS ve FKS'si ile BDÖ arasında ise negatif yönde bir korelasyon tespit edildi (Tablo 3).
Sakarya Tıp Dergisi

2018;8(2):371-378

ÜREYEN ve Ark.

Ankilozan Spondiliti Olan Hastalarda Depresyonun

Hastalik Aktivitesi ve Yaşam Kalite Ölçekleri Üzerine Etkileri 


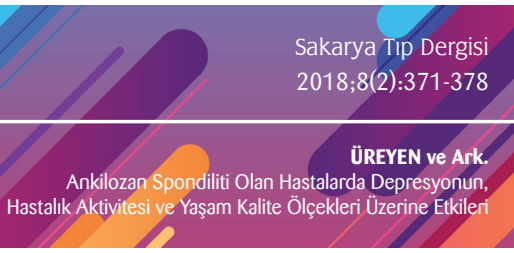

Tablo 3. Beck Depresyon Ölçeği ile yaşam kalite ölçekleri ve aktivite parametreleri arasındaki korelasyonun değerlendirilmesi.

\begin{tabular}{|l|c|c|c|}
\hline & \multicolumn{3}{|c|}{ Beck Depresyon Ölçeği } \\
\hline BASFi & $r$ & $\rho$ & $n$ \\
\hline BASDAi & 0.399 & $<0.001$ & 131 \\
\hline Beck Anksiyete Ölçeği & 0.387 & $<0.001$ & 131 \\
\hline MKS & 0.736 & $<0.001$ & 129 \\
\hline FKS & -0.708 & $<0.001$ & 129 \\
\hline ASQoL & -0.454 & $<0.001$ & 129 \\
\hline EQ5D & 0.574 & $<0.001$ & 130 \\
\hline HAQs & 0.573 & $<0.001$ & 126 \\
\hline Gece ağrısı (VAS) & 0.464 & $<0.001$ & 131 \\
\hline Genel ağrı (VAS) & 0.372 & $<0.001$ & 130 \\
\hline Hastalık aktivitesi (VAS) & 0.307 & $<0.001$ & 129 \\
\hline Genel sağlık (son hafta) (VAS) & 0.427 & $<0.001$ & 128 \\
\hline Genel sağlık (son 6 ay) (VAS) & 0.442 & $<0.001$ & 128 \\
\hline
\end{tabular}

ASQoL: Ankilozan Spondilit Yaşam Kalitesi Ölçeği; BASDAi:Bath Ankylosing Spondylitis Hastalık Aktivite İndeksi; BASMi: Bath Ankylosing Spondylitis Metroloji İndeksi; BASFi: Bath Ankylosing Spondylitis Fonksiyonel İndeksi; EQ5D: EuroQuol 5D; HAQs: Spondiloartritler için sağlık değerlendirme anketi (Health Assessment Questionary For The Spondylarthropathies); MKS: mental komponent skoru; FKS: fiziksel komponent skoru; VAS: görsel analog skala (visual analogue scale).

BASDAi $\geq 4$ üzerinde olan AS hastalarında depresyon sıklı̆ı 1.55 kat (\%95 güvenlik aralığında 1.043-2.31, $p<0.05)$ artarken, bu grupta anksiyete sıklığı ise 1.88 kat (\%95 güvenlik aralığında 1.275-2.791, $p<0.05)$ artmıştır. BASFi $\geq 4$ üzerinde olanlarda anksiyete sıklığı 2.06 kat (\%95 güvenlik aralı̆ında 1.318-3.233, $p<0.05)$ artmıştır.

\section{Tartışma:}

Çalışmamızda, AS hastalarının yaşam kalitelerini birçok farkı açıdan değerlendirebilen yaşam kalite ölçekleri (ASQoL, EQ5D, kısa form SF-36, HAQs, gece ağrısı VAS, genel ağrı VAS, hastalık aktivitesi VAS, genel sağlık (son hafta ) VAS ve genel sağlık (son 6 ay) VAS), geniş bir hasta grubunda bir arada kullanıldı. Bizim hasta grubumuzda depresyon oranı $\% 27.5$, anksiyete oranı ise $\% 33.6$ olarak bulundu. Bu sonuçlar literatürde gözlenen oranlar ile uyumluydu. ${ }^{4-7}$ BDÖ'e göre depresyon tespit edilen hastalarda, hastalık aktivite ölçekleri yüksek, yaşam kaliteleri olumsuz yönde etkilenmiş ve anksiyete görülme oranı da artmıştı.

AS hastalarında yaşam kalitesi ile ilişkili faktör olarak bugüne kadar en fazla sigara araştıııımıştır. Sigara, daha önceki bir çalışmada akciğer fonksiyonlarının bozulması ve hastalığa bağı kısıtlıık oranında artış ile ilişkili bulunmuştur. ${ }^{20}$ Sigara kullanımı ile depresyon varlığı açısından bizim çalışmamızda anlamlı bir fark tespit edilmedi. Farkı bir çalışma da, AS hastalarında BDÖ ve BAÖ, kontrol grubuna göre daha yüksek saptanmış ve hatta kadın AS hastalar arasında depresyon daha yüksek oranda gözlemlenmiştir. ${ }^{9}$ Bizim çalışmamızda ise cinsiyet açısından depresyon tespit edilen ve edilmeyen hastalar arasında anlamlı bir fark bulunmadı. Ayrıca, bu çalışmada AS hastalarında görülen depresyon düzeyindeki artışın, hastalı̆ın kendi doğasından kaynaklanan immünolojik değişiklikle- 
rin sonucu olabileceği de vurgulandı. ${ }^{9}$ Kaan ve ark'nın yaptıkları bir çalışmada BDÖ ile BASDAi ve BASFi arasında bir korelasyon tespit edilemediği raporlanırken, bazı çalışmalarda bu parametreler arasında ciddi bir korelasyon gösterildi. ${ }^{8,9}$ Buna karsın, biz çalışmamızda BDÖ’e göre depresyon olan hastalarda aktivite ve fonksiyon parametreleri arasında ciddi bir korelasyon tespit ettik ve hatta BASDAI $\geq 4$ üzerinde olması depresyon riskini 1.55 kat artırdığını saptadık. Bir çalışada tumor necrosis factor (TNF) inhibitör tedavilerinin kullanımının, depresyon semptomlarında iyileşme ile ilişkili olduğu bulundu, fakat bizim çalışmamızda TNF inhibitör tedavi kullanımı ile BDÖ arasında anlamlı bir ilişki gözlenmedi. ${ }^{21}$

Hastalığı aktif olan AS grubunda ağrı, kısıtlılık, tutukluk, yorgunluk uyku bozukluğu, depresyon gelişimine katkı sağlayabilirken, depresyonu olan hasta grubunda ise depresyonun nedeniyle interferon (IFN)- alpha, interleukin (IL)-1, IL-6 ve TNF-alfa gibi sitokin artışları sonucu immün sistemin uyarılması da hastalık aktivasyonuna katkı sağlayabilmektedir. Depresyon hastalık aktivitesine, hastalık aktivitesinin artışı da depresyon gelişimine katkı sağlıyor gibi görünmektedir. ${ }^{22}$

Çalışmamızın bazı kısıtlııkları bulunmaktadır. Bunlardan birisi sağıklı kontrol grubunun olmamasıdır. Fakat, çalışmamızın birincil amacı AS hasta grubunda BDÖ ile tespit edilen depresyon sıklı̆ı̆ı belirlemek olduğu için sağlıkı kontrol kullanılmamıştır.

Sonuç olarak, biz çalışmamızda depresyonu olan AS hastalıklarında, hastalık aktivite parametrelerinin daha yüksek olduğunu, bedensel, zihinsel, duygusal ve sosyal iyilik halinin ciddi ölçüde bu hastalıktan etkilendiğini gözlemledik. Psikiyatrik durum değerlendirmesi klinik değerlendirmenin bir parçası olarak düşünülebilir ve depresyonunun olumsuz yönde etkilediği yaşam kalitesindeki bu bozulmaların iyileştirilmesi, tedavi planının bir parçası olarak değerlendirilebilir.
Sakarya Tıp Dergisi

2018;8(2):371-378

ÜREYEN ve Ark. Ankilozan Spondilititi Olan Hastalarda Depresyonun. Hastalik Aktivitesi ve Yaşam Kalite Ölçekleri Üzerine Etkileri

Çıkar ilişkisi: yok 
1. Braun J, Sieper J. Ankylosing spondylitis. Lancet 2007;369:1379-1390.

2. Will R, Edmunds L, Elswood J, Calin A. Is there sexual inequality in ankylosing spondylitis? A study of 498 women and 1202 men. J Rheumatol 1990;17:1649-52

3. Dalyan M, Guner A, Tuncer S, Bilgic A, Arasil T . Disability in ankylosing spondylitis. Disabil Rehabil 1999; 21:74-79.

4. Ozgül A, Peker F, Taşkaynatan M. A. Ankilozan spondilitte hastalığın yaşam kalitesi ve yaşam alanlarına etkisi. Romatizma 2003; 18: 82-91.

Sakarya TIp Dergisi 2018;8(2):371-378

ÜREYEN ve Ark. Ankilozan Spondiliti Olan Hastalarda Depresyonun,
5. Barlow JH, Macey SJ, Struthers GR. Gender, depression, and ankylosing spondylitis. Arthritis Care Res 1993;6:45-51.

6. Hyphantis T, Kotsis K, Tsifetaki N, Creed F, Drosos AA, Carvalho AF, et al. The relationship between depressive symptoms, illnessperceptions and quality of life in ankylosing spondylitis in comparison to rheumatoid arthritis. Clin Rheumatol 2013;32:635-44.

7. Hakkou J, Rostoms, AissaouiN, BerradakR, Abouqal R, Bahiri R, et al.Psychological status in Moroccan patients with ankylosing spondylitisand its relationships with disease parameters and quality of life. J Clin Rheumatol 2011;17:424-8.

8. Martindale J, Smith J, Sutton CJ, Grennan D, Goodacre L, Goodacre JA Disease and psychological status in ankylosing spondylitis. Rheumatology 2006;45:1288-1293.

9. Eren I, Sahin M, Cure E, Inanlı IC, Tunc SE, Kucuk A. Interaction between psychiatric symptoms and disability and quality of life in ankylosing spondylitis patients. Arch Neuropsychiatry 2007;44:1-9.

10. Van der Linden S, Valkenburg H, Cats A. Evaluation of diagnostic criteria for anklosing spondylitis: A proposal for modification of the New York criteria. Arthritis Rheum 1984; 27: 361-368.

11. Hisli N. Beck Depresyon envanterinin geçerliliği üzerine bir çalışma. Psikoloji Dergisi 1988; 22:118-126.

12. Ulusoy M, Sahin NH, Erkmen H. Turkish version of the Beck Anxiety In ventory: Psychometric properties. J Cogn Psychother 1998;12: 163-172.
13. Jones SD, Steiner A, Garrett SL, Calin A. The Bath Ankylosing Spondylitis Patient Global Score (BAS-G). Br J Rheumatol 1996;35:66-71.

14. Garrett S, Jenkinson T, Kennedy LG, Whitelock H, Gaisford P, Calin A. A new approach to defining disease status in ankylosing spondylitis: The Bath Ankylosing Spondylitis Disease Activity Index. J Rheumatol 1994; 21: 2286-2291.

15.Jenkinson TR, Mallorie PA, Whitelock HC, Kennedy LG, Garrett SL, Calin A. Defining spinal mobility in ankylosing spondylitis (AS). The Bath AS Metrology Index. J Rheumatol 1994; 21: 1694-1698.

16. Doward LC, Spoorenberg A, Cook SA, Whalley D, Helliwell PS, Kay L) et al. Development of the ASQoL: a quality of life instrument specific to ankylosing spondylitis. Ann Rheum Dis2003; 62: 20-26.

17. Johnsen LG, Hellum C, Nygaard OP, Storheim K, Brox Jl, Rossvoll I, et al. Comparison of the SF6D, the EQ5D, and the owwestry disability index in patients with chronic low back pain and degenerative disc disease. BMC Musculoskelet Disord. 2013;14:148.

18. Farivar SS, Cunningham WE, Hays RD. Correlated physical and menta health summary scores for the SF-36 and SF-12 Health Survey, V.1. He alth Qual Life Outcomes. 2007; 5: 54.

19. Rohde G, Berg KH, Prøven A, Haugeberg G. The relationship between demographic- and disease-related variables and health-related quality of life in patients with axial spondyloarthritis. BMC Musculoskelet Disord 2017; $18: 328$

20. Kaan U, Ferda O. Evaluation of clinical activity andfunctional impairment in smokers with ankylosing spondylitis. Rheumatol Int 2005; 25: 3573-60.

21. Ersözlü-Bozkırlı ED, Keșkek SO, Bozkırlı E, Yücel AE. The effect of infliximab on depressive symptoms in patients with ankylosing spondylitis. Acta Reumatol Port 2015;40:262-267.

22. Raison CL, Capuron L, Miller AH. Cytokines sing the blues: inflammation and the pathogenesis of depression. Trends Immunol 2006;27:24-31. 